\title{
Modeling and Investigating the Behavior of Viscous Dampers in Steel Structures
}

\author{
Mohmmad Masoud Ghiabi \\ Department of architecture ,Faculty of Engineering, Technical University of Ilam, Ilam ,Iran \\ Email : mohamadmasoudghiabi@gmail.com
}

\begin{abstract}
Viscous dampers are generally effective in controlling the vibrations stemming from the wind in the steel structures as well as in excitements with frequency band identical to that of these dampers. Tuned viscous damper is a passive control system the parameters of which are determined based on the structure's preliminary specifications and always remain fixed. The primary goal of this study is observing the nonlinear behavior and evaluating the seismic performance of the steel structures with specific steel moment frames equipped with viscous damper under mass and damping uncertainty conditions of the structure as well as in respect to the elastic modulus and yield stress in steel. This evaluation has been carried out by the assistance of ETABS and Sketch-Up Software Packages with the time history analysis having been conducted in Sap2000 Software. To do so, three steel 3-, 9- and 12-storey structures with residential use have been considered on an earthquake-prone region. The study results indicated that the storey's drift and dislocation have been considerably reduced. Thus, it can be concluded that the use of viscous damper is an appropriate method for controlling the structures' dislocation. It was also found out that the emergence of disorder in the structure's mass and damping has a greater effect in contrast to the other two parameters on the response of the structure equipped with viscous damper.
\end{abstract}

Keywords: viscous dampers, tuned dampers, seismic performance, steel structures

\section{Introduction:}

When earthquakes occur, the energy resulting thereof enters the structure and it has to cause depreciation of this energy through displacement. Structures can well deform beyond the elastic limits subject to an intensive earthquake and they can even remain intact only for their non-elastic deformation and, unfortunately, such deformations can result in the topical destruction of the structure because the structure itself should absorb most of the input energy. Now, it is here that the energy dissipation and depreciation systems and devices gain distinct importance. The new approach to the structures' designing and improvement makes use of structure controlling systems. These controlling systems' mechanism of action is laid on the foundation of the idea that the demand is reduced instead of increasing the hardness and strength; these controlling systems depreciate a large part of the input energy and cause reductions in the dislocation and vibration of the structure. They are divided into three sets of active, semi-active and passive controlling systems based on the quality with which the activation energy is supplied. The studied tuned viscous dampers fall in the passive set. This damper is installed on the floor of one or several storeys of the building hence it can be also applied as a tool for reinforcement [1].

These dampers were seminally proposed based on the studies that had been carried out on the dynamic vibration and shock absorbers by Frahm and their results were published in 1909 [2]. Urmondroid and Dan Hartog expanded a more complete model of the shock absorbers in 1928.

In his book "mechanical vibrations" that was published in 1956, Dan Hartog offered the codified shock-absorbers theory in a state that the main structure is without damping within the format of the analytical mathematical equations [4]. Bishop and Wellborn discussed about the vibrating shock-absorbers by considering the effect of a damper's existence in the main structure.in 1967, Falcon followed Bishop's works and dealt with the statement of an optimization problem for the parameters of viscous dampers. In 1981, Randall published tables about the designing of these dampers' parameters. Other similar tables have also been offered by other researchers based on the various scales for optimizing the controlling of main structure's harmonic oscillation. During the past years, the effect of frequency adjustment disorder and/or other viscous dampers' parameters has been investigated by the researchers. Rana and Song evaluated the effects of such disorders in the linear structures [1]. Bagheri and Rahmani Dabbagh eliminated the viscous dampers in 2018 and replaced it by a system with elastoplastic springs in a tuned mass damper (TMD) for controlling the seismic response of a new system. The numerical results indicated that the proposed devise considerably reduces the seismic responses and can be used instead of TMD without any need for viscous damper [5]. Karami et al performed nonlinear structural control using integrated DDA/ISMP in a tuned viscous damper and figured out that the proposed STMD controller is capable of reducing the damage caused by any structural frequency changes and nonlinear dynamic responses subject to the strong seismic motions [6]. Batu and Adikary investigated the optimal parameters of the viscous dampers in 2019 and concluded that the use of a viscoelastic TMD is excellently capable of inversely absorbing the vibration in comparison to a TMD counterpart [7]. Vontill et al (2019) dealt in a study with the modeling of the nonlinear 
frequency range and the cessation behavior for tuned viscous dampers subject to uni- and multi-harmonic excitements and found out that BTMDs enable an effective vibration controlling strategy that can be implemented via various damping options and also that the two homogeneous and contact friction mechanisms are promising examples for creating an independent domain in the pendulum engineering systems [8].

Kayhani et al (2015) probabilistically evaluated the effect of the inherent and cognitive uncertainties on the seismic performance of the steel structures equipped with tuned viscous dampers and found out that the emergence of disorder in the structure's mass and damping has a greater effect in contrast to the other two parameters on the response of the structure equipped with viscous damper [9]. Ashrafi and Alamatian (2015) designed a viscous damper for a non-damped structure by combining the stable and transient responses and assessing the applied viscosity ratios in a study and expressed that the response of the structure controlled by this viscous damper is more likely to be smaller than that controlled by the other dampers [10]. Sayyar et al (2017) showed in a study under the title of "investigating the effect of tuned viscous dampers on the behavior of the steel moment frame structures in various earthquakes" that the storeys' dislocation and drift undergo notable reductions so it can be concluded that the use of viscous damper is a proper method for controlling the structures' displacement [11]. Farrokhi and Rahimi (2017) concluded in a study titled "probabilistic evaluation of the performance of viscous dampers in tall steel structures" that the use of viscous dampers on all the studied structure's storeys leads to the considerable reduction in the destruction likelihood [12]. Rahmani Dabbagh (2018) evaluated and controlled the seismic vibrations of the structural systems with real and nonlinear behavior through the use of the tuned viscous dampers and showed that the change in the optimal amounts of the viscous dampers' parameters depends on the main system's yield levels and also that the viscous dampers are also effective in the reduction of the responses exhibited by the main system with nonlinear behaviors; however, it was found out that this efficiency is reduced in most of the cases with the reduction in the yield level [13]. ।

The seismic response of the buildings can be reduced and improved by the assistance of the tuned viscous dampers. Thus, the present study has dealt with the nonlinear behavior through evaluating the seismic performance of the steel structures with specific steel moment frame systems equipped with viscous dampers in respect to the mass and damping uncertainties of the structure as well as the elastic modulus and yield stress; the optimal mass and damping changes have been simultaneously determined in regard of the improvement in the structure's seismic performance.

\section{Viscous Dampers:}

In the novel methods of seismic designing, there are two perspectives for fighting with the earthquakes' energy. The first perspective includes methods that cause reduction in the force exerted onto the structure by separating the structure from the ground vibrations with the base isolation systems falling in this set. In the second perspective, the intention is substituting the damping equipment in line with depreciation of the seismic energy. Such equipment dissipates part of the earthquake's energy and bring about reductions in the damage caused by inelastic behaviors.

The base isolation's philosophy is separating the structure from the ground vibration and this is done via rendering the structure flexible through the use of a mechanism underneath the structure along with the creation of proper damping. One of the primary advantages of the isolated structures is their elastic behavior in moderated to mild earthquakes.

Viscous dampers constitute one of the passive controlling systems placed in a braced and restraint location to absorb part of the seismic energy imposed to the structure which reduces the energy depreciation demand on the structure's elements and causes the structural damage and destruction to be minimized. The normal structures absorb energy by yielding or disintegration of the constructional materials. For example, the seismic energy is absorbed by the formation of plasticity in the steel beams and columns and by the creation of cracks in the concrete structures.

Viscous dampers offer a solution for yielding or disintegration. These dampers supply a force that always resists the structure's movement. This force is in proportion to the relative velocity of the dampers' two heads.

\section{Viscous Dampers' Mechanism of Action:}

In some of the isolation systems, damping is supplied by viscous dampers. The application of the viscous dampers with linear and nonlinear behavior functions in the isolated structures has been studied under the states in near and far areas.

These dampers' mechanism of action is in the form of cylinder-piston. There are three chambers inside the cylinder: one on the right side of the piston, one on the left side thereof and one in the farthest end of the right side. There are holes in the piston and there is also liquid inside cylinder which is either oil or a condensable liquid. When piston moves in cylinder, its movement causes the displacement of the liquid from the orifice positioned on the piston's head. The movement of the liquid from amongst these holes causes the depreciation of energy or, in other words, the energy is dissipated in the form of heat. 
In some of the isolation systems, damping is supplied by means of viscous dampers. The application of the viscous dampers with linear and nonlinear behavior functions in the isolated structures has been studied under the states in near and far areas. Viscous dampers offer a solution in the form of either yielding or disintegration. These dampers supply a force which can always resist against the movement of the structure. This force is in proportion to the relative velocity of the dampers' two heads.

\section{Tuned Viscous Damper:}

A tuned viscous damper is a devise composed of a mass, a spring and a damper connected to the structure and its objective is reducing the structure's dynamic response. The damper's frequency is adjusted to the frequency of a given structure so that the activation of this frequency results in the movement of the damper with phasic difference in respect to the structure's movement. Figure (1) illustrates a simplified view of the viscous dampermain structure's interactions. Parameters $\mathrm{K}_{\mathrm{s}}, \mathrm{C}_{\mathrm{s}}$ and $\mathrm{M}_{\mathrm{s}}$ respectively denote the mass, depreciation and hardness of the main structure and parameters with subscript " $\mathrm{d}$ " are expressive of the equivalent amounts for the damper. If Ud, Us and Ug respectively indicate the main structure's displacement in respect to the support, the damper's displacement in respect to the main structure and the support's displacement, the differential equations of the system's dynamic balance can be written in the following forms [14]:

$$
\begin{array}{ll}
\mathrm{s}+\mathrm{Ks} \text { us }=-(\mathrm{Ms}+\mathrm{md}) \mathrm{u} \mathrm{g}-\mathrm{md} & (\mathrm{Ms}+\mathrm{md}) \mathrm{s} \mathrm{s}+\mathrm{Cs} \\
\text { ù d } & \\
\mathrm{d}+\mathrm{Kd} \mathrm{ud}=-\mathrm{md}(\text { ùs }- \text { ü }) & \text { md ùd }+\mathrm{Cd}
\end{array}
$$

\section{Models:}

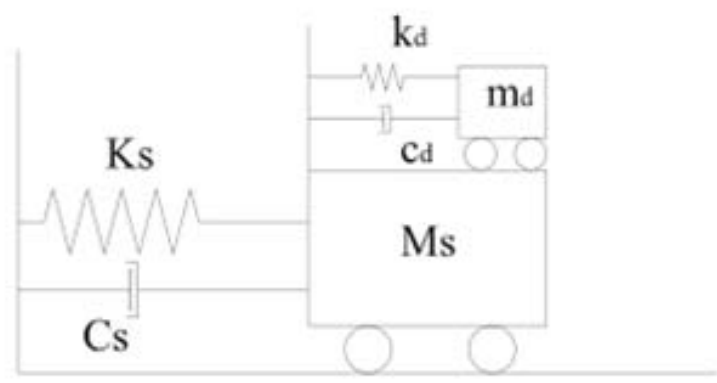

The designing and analysis of the structures' model was seminally carried out statically using ETABS Software and by the aid of AISC360-10 Guidelines. Then, the scaled spectra were exerted for the analysis of the time history in SAP2000 onto the structures. Based thereon, three models of 2D steel frames were taken into account. The details and specifications of the structures' models and cross-sections have been given in tables (1) and (2).

Table 1: specifications of the structures' models for the 3-, 9- and 12-storey buildings with three 5-meter spans in steel moment frame with specific ductility

\begin{tabular}{|l|l|}
\hline Storeys' height & $3.20 \mathrm{~m}$ \\
\hline Type of the soil & 3 types \\
\hline Ratio of the project's basic acceleration & Region with a relatively very high risk \\
\hline Steel type & Steel type 37 \\
\hline Elasticity modulus & $2.1 \times 10^{6} \mathrm{~kg} \cdot \mathrm{cm}^{2}$ \\
\hline Steel's yield stress & $2400 \mathrm{~kg} / \mathrm{cm}^{2}$ \\
\hline Steel's final stress & $3700 \mathrm{~kg} / \mathrm{cm}^{2}$ \\
\hline Loading & Based on chapter six of Iran's national building regulations [16] \\
\hline Structure's design & $\begin{array}{l}\text { Based on chapter ten of Iran's national building regulations [17] } \\
\text { and journal of seismic improvement, no.360 [18] }\end{array}$ \\
\hline Damping ratio & $5 \%$ \\
\hline
\end{tabular}


Table 2: cross-sections of the intended frame's elements and the main structure's fundamental period

\begin{tabular}{|c|c|c|c|c|c|c|}
\hline \multirow{2}{*}{$\begin{array}{c}\text { Storey } \\
\text { number }\end{array}$} & \multicolumn{2}{|c|}{$\begin{array}{c}\text { 12-storey structure=2.05 } \\
\text { seconds }\end{array}$} & \multicolumn{2}{c|}{$\begin{array}{c}\text { 9-storey structure=1.07 } \\
\text { seconds }\end{array}$} & \multicolumn{2}{c|}{$\begin{array}{c}\text { 3-storey structure=0.92 } \\
\text { seconds }\end{array}$} \\
\cline { 2 - 7 } & IPB column & IPE beam & IPB column & IPE beam & IPB column & IPE beam \\
\hline 12 & 240 & 270 & - & - & - & - \\
\hline 11 & 260 & 300 & - & - & - & - \\
\hline 10 & 260 & 300 & - & - & - & - \\
\hline 9 & 260 & 300 & 180 & 300 & - & - \\
\hline 8 & 260 & 300 & 200 & 300 & - & - \\
\hline 7 & 270 & 330 & 220 & 300 & - & - \\
\hline 6 & 300 & 330 & 220 & 330 & - & - \\
\hline 5 & 300 & 330 & 240 & 330 & - & - \\
\hline 4 & 320 & 360 & 240 & 330 & - & 240 \\
\hline 3 & 320 & 360 & 240 & 360 & 160 & 270 \\
\hline 2 & 320 & 360 & 260 & 360 & 180 & 270 \\
\hline 1 & 320 & 360 & 280 & 400 & 200 & - \\
\hline
\end{tabular}

Materials and Method:

\section{A) Model's Loading:}

Loading Specifications (Static and Seismic): the amounts of the dead load were set at $600 \mathrm{~kg} / \mathrm{m}^{2}, 200 \mathrm{~kg} / \mathrm{m}^{2}$ and $300 \mathrm{~kg} / \mathrm{m}^{2}$ for the storeys in static loading according to Iran's 2800 guidelines [19]. Efforts were made in selecting the structures' models that the models represent the normal building structures existent in Iran. The specific moment frame has been used in the present research paper for its high behavioral coefficient in contrast to the other structural systems. Moreover, it plays an optimal role in rendering the structure more cost-effective.

- Combining the Nonlinear Static Gravitational and Lateral Loading: in order to analyze and design the structures, use was made of a combination of gravitational and lateral loading according to the tenth chapter and direct integral method with the exertion of $\mathrm{P}$ effect was the method of choice for loading the time history.

\section{B) Accelerograms:}

- Accelerograms have been extracted according to the near fault earthquake's distance from the reference (Berkeley site) [20]. As for the number of the accelerographs used for the dynamic analysis of the time history according to paragraph (2-5-3-2) of Iran's 2800 earthquake guideline, three accelerographs should be applied on every stretch. In this study, in order to estimate the seismic response, use has been made of a larger number, five, accelerographs in near area as shown in table (3). The accelerograms have been scaled to $1.00 \mathrm{~g}$ and the intended analyses have been performed in the domain of time history.

Table 3: specifications of the near-fault earthquake records (Berkeley Site) [19]

\begin{tabular}{|l|l|l|l|l|}
\hline Row & Earthquake record & History & Station & Sheer wave velocity \\
\hline 1 & Tabas & 1978 & TAB & 244.80 \\
\hline 2 & Manjil & 1990 & MAN & 301.44 \\
\hline 3 & Northridge & 1994 & ARL & 316.50 \\
\hline 4 & Kobe & 1995 & KJM & 312.00 \\
\hline 5 & Loma Prieta & 1989 & BRN & 268.70 \\
\hline
\end{tabular}

\section{C) Plastic Joint:}

In order to define the plastic joint of the beams and columns within the studied frames, use has been made of the criteria in the instructions for the seismic improvement of the existing buildings (journal no.360, tables 2-5). Furthermore, joint control has been conducted in the time history analysis for the public buildings with risk level C-3,1 (LS-Life Safety) according to table (C-A) in the foresaid journal, no.360[18]. 


\section{D) Calculation of the Optimal Parameters for Tuned Viscous Damper in a Multiple-Degree-of-Freedom System with 5\% Damping:}

In this study, the structures' dynamic specifications were calculated assuming the certainty of all the parameters (values given in table 4) and use was subsequently made of the coefficients suggested in the reference to determine the optimal parameters of the viscous damper based on the first mode according to the following relations. The quantitative values of these parameters have been given in table (5). It is worth mentioning that parameters md, $\mathrm{cd}, \mathrm{kd}$ and $\mathrm{d}$ in the recent relations pertain to the damper and they respectively mean mass, damping, hardness and frequency; $\mathrm{M}$ also denotes the structure's general mass. Due to the operational problems related to the optimal mass ratio, the building's overall mass has been set at 5\%. In this study, uncertainty of the damper's elements has not been taken into consideration and they have been excluded from the present study's goals.

Table 4: random specifications of the studied parameters

\begin{tabular}{|l|l|l|l|}
\hline Variable parameter & Mean & Variations coefficient (C.O.V) & Standard deviation \\
\hline Yield strength & 2400 & $10 \%$ & 240 \\
\hline Elastic modulus Fy $\left(\mathrm{kgf} / \mathrm{cm}^{2}\right)$ & $2.1 \times 10^{6} \mu$ & $5 \%$ & $105000 \sigma$ \\
\hline Structure's damping Fy $\left(\mathrm{kgf} / \mathrm{cm}^{2}\right)$ & $5 \%$ & $30 \%$ & $1.5 \%$ \\
\hline Change in mass & 16 & $10 \%$ & 1.6 \\
\hline
\end{tabular}

Table 5: optimal specifications of the damper used in the frames

\begin{tabular}{|l|l|l|l|l|}
\hline & Mass & Damping & Spring's hardness & Unit parameter \\
\hline 3-storey & 137.5 & 8.20 & 3.60 & $5 \%$ \\
\hline 9-storey & $116.4 \mathrm{kgf} / \mathrm{cm}$ & $14.36 \mathrm{kgf}^{-\mathrm{s}} / \mathrm{cm}$ & $10.80 \mathrm{kgf}^{-\mathrm{s} 2} / \mathrm{cm}$ & $5 \%$ \\
\hline 12-storey & 107 & 15.95 & 14.40 & $5 \%$ \\
\hline
\end{tabular}

Results of Models' Analysis:

\section{1) Brittleness Analysis:}

In this study, the brittleness curves have been prepared in an analytical method through the use of the incremental dynamic analysis. In this analysis, use has been made of the old concept of scaling the ground motions' records and its development in such a way that the building's capacity and demand amounts can be covered with appropriate accuracy in a vast domain of the elastic behavior to the building's destruction. In fact, the absence of the sufficient information about the earthquake with various intensities corresponding to the locality's conditions for the investigation of the structure's seismic behavior made the researchers use fixed coefficients for the existent accelerograms to fill the gap in the records with absent intensities. The applied accelerograms should be well reflective of the earthquake source's properties, the fault's mechanism of action, distance from the fault, magnitude and construction site's properties. In a statistical study, the number of the considered accelerographs in addition to the characteristics of each accelerogram is of a great importance meaning that the larger the number of the accelerograms, the lower the uncertainty about the earthquake properties. In this study, five earthquake records were withdrawn from PEER website for performing the dynamic analysis; they have been summarized in table (3). After drawing the spectral response of each pair of the accelerograms and their comparison, the main record's indicator was determined based on the larger spectral values in the building's vibrational frequency domain and used for performing the analyses. The intensity of the earthquakes imposed on the structure has been increased incrementally in the course of the analyses with the consideration of the parameter IM and DM as the outputs of the analysis or, better said, the structure's response to excitement. IDA curves actually show the relationship between the structure's response, DM, in respect to the change in the intensity of the accelerograms, IM. In this study, the spectral acceleration of the structure's first case of dislocation was selected for defining the intensity parameter assuming a 5-percent damping. Considering the highest relative inter-storey displacement as the response parameter, the destruction levels were defined as presented in table (6) and the probability of leaving these destructions' states were delineated per various levels of risk (figures 1 and 2). 
Table 6: classification of the states of seismic damage in quantitative terms

\begin{tabular}{|l|l|l|l|l|}
\hline \multirow{2}{*}{$\begin{array}{l}\text { Specific moment } \\
\text { frame }\end{array}$} & \multicolumn{4}{|c|}{ States of damage and relative inter-storey displacement corresponding to each } \\
\cline { 2 - 5 } & Mild damage & Intermediate damage & Extensive damage & Perfect damage \\
\hline 3-storey frame & 0.006 & 0.0100 & 0.024 & 0.06 \\
\hline 9-storey frame & 0.004 & 0.0067 & 0.016 & 0.04 \\
\hline 12-storey frame & 0.003 & 0.0050 & 0.012 & 0.03 \\
\hline
\end{tabular}

In order to draw the brittleness curves, as shown in figure (1), the amounts of the spectral acceleration were extracted for every limit state (performance level) from the incremental dynamic analysis. In another step and assuming that the natural logarithm of the obtained values features normal distribution, the mean and standard deviation are calculated for the extracted amounts so as to extract a probability density function $\mathrm{F}(\mathrm{x})$ for every limit state. The repetition of this procedure and extraction of the probability amounts for various intensities result in the extraction of the brittleness curve for the intended performance levels.

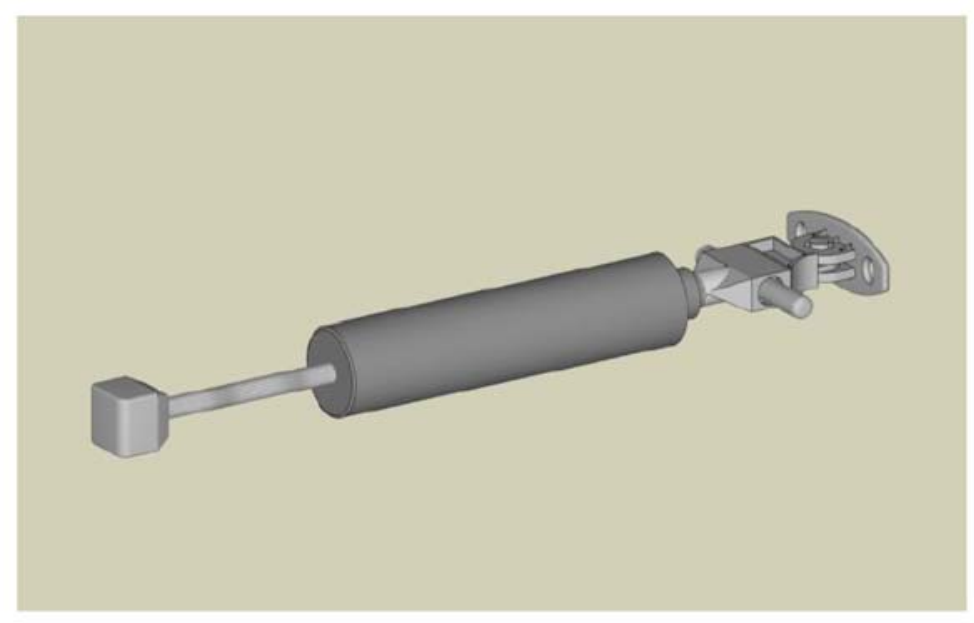

(1): simulated model of the viscous damper

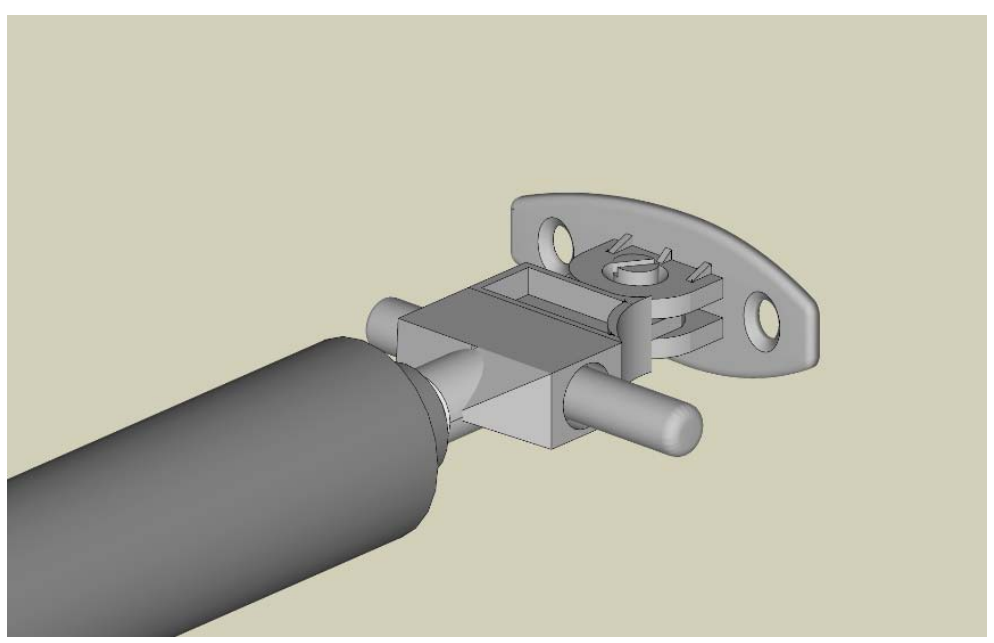

(2): simulated model of the viscous damper 


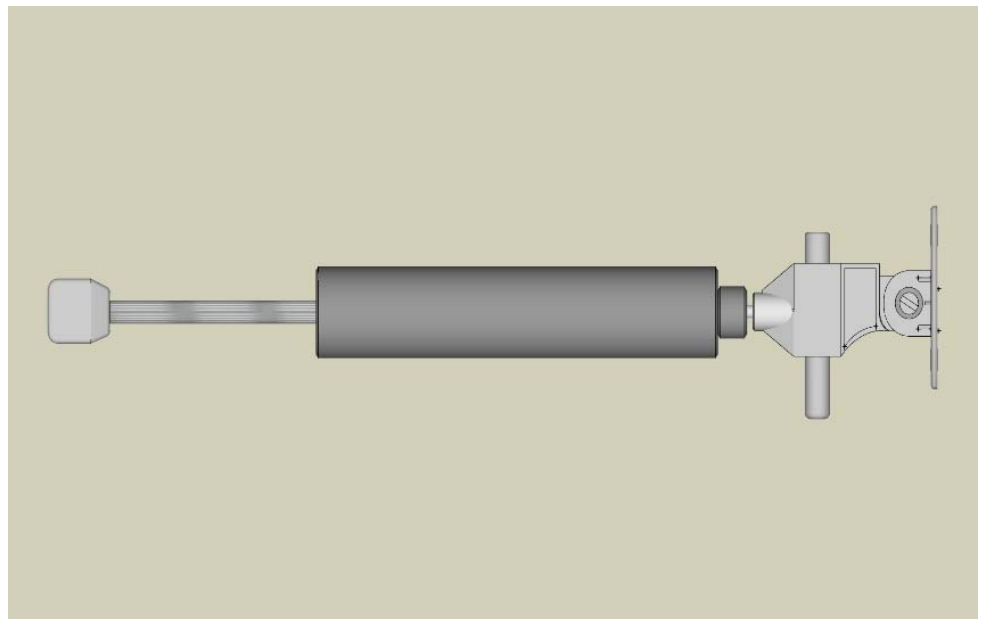

(3): simulated model of the viscous damper
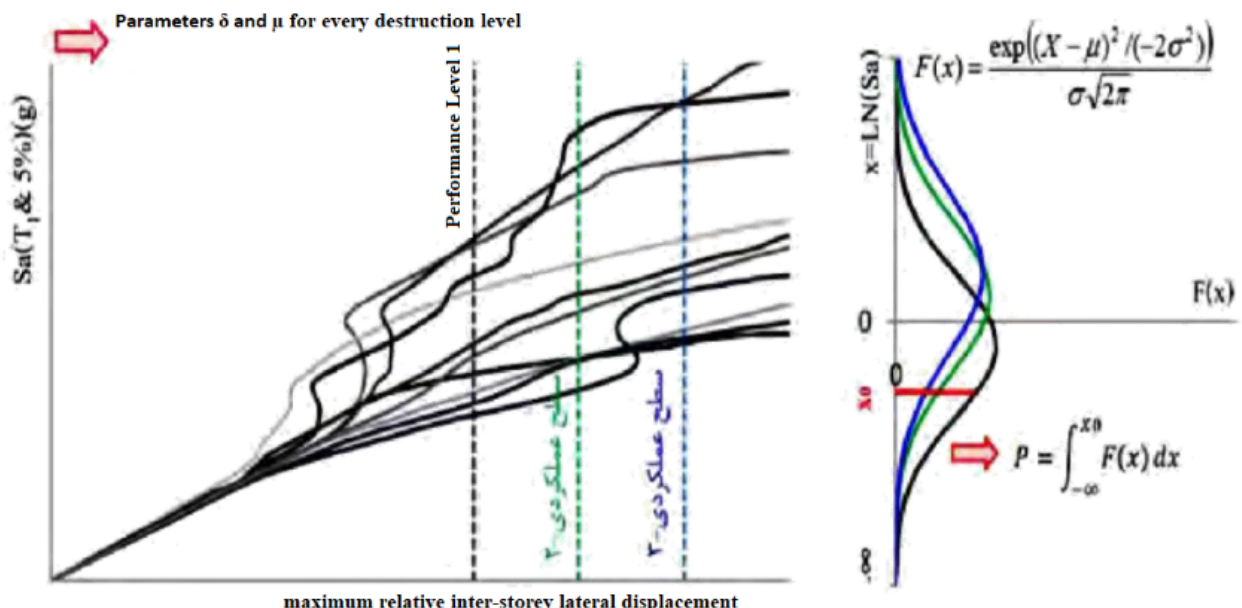

Figure (1): likelihood of moving from one fixed performance level in a hypothetical risk level (schematic)

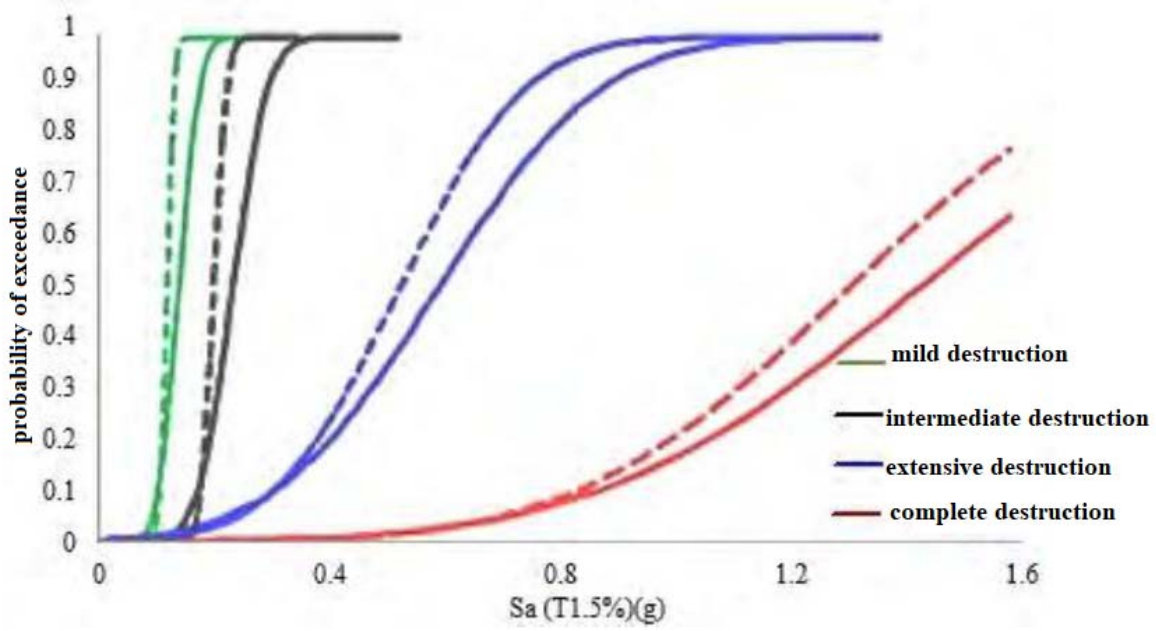

a) 3-Storey Frame 


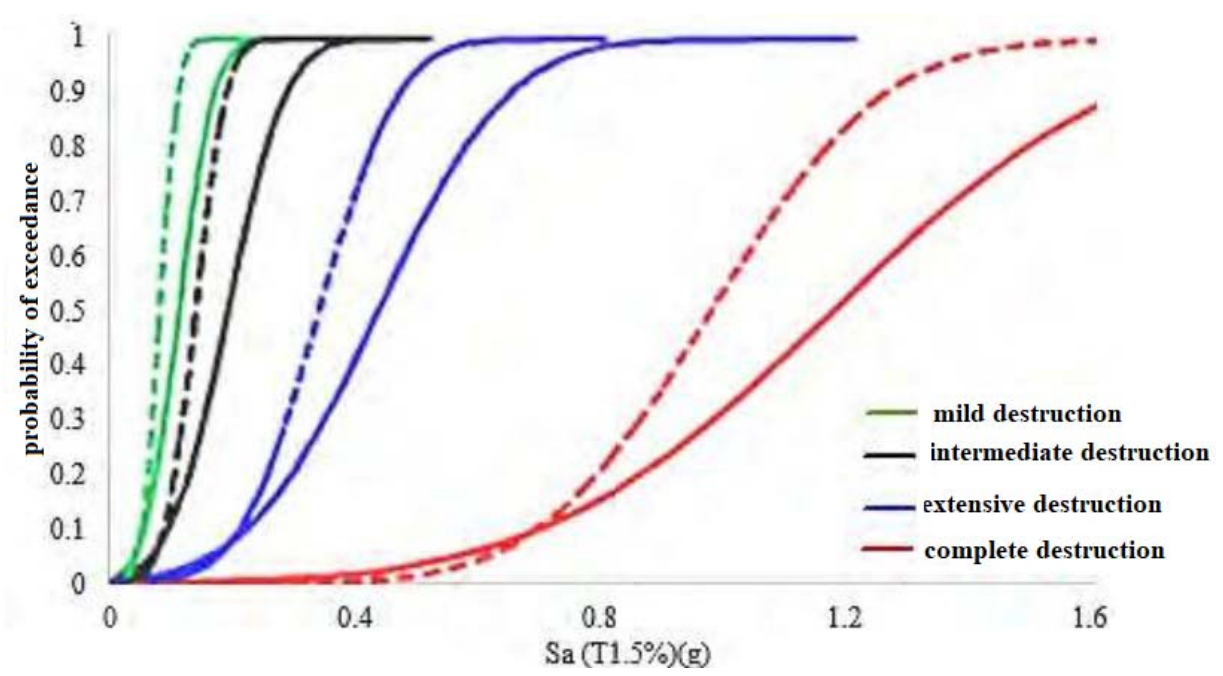

b) 9-storey frame

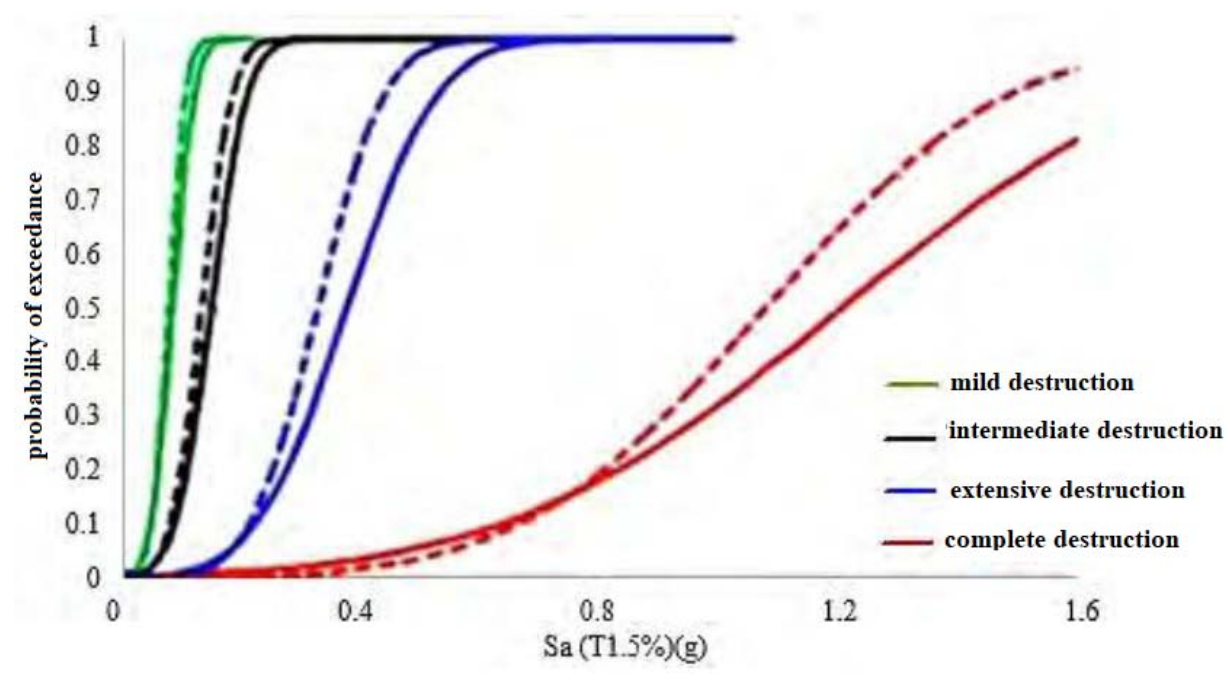

c) 12-storey frame

Figure (2): comparison of the brittleness curves of the structure equipped with tuned damper and the structure not equipped with tuned damper along with the average specifications (dotted line)

As it was expected, the use of viscous damper causes reduction in the destruction likelihood and improvement in the structure's performance. According to figure (2), the destruction likelihood is almost similar in SD and MD performance levels for the 3-storey and 12-storey frames equipped with damper as compared to the frames without damper. Of course, it was quite expectable because the goal of structures' seismic designing is the safeguarding the life security in the high destruction levels and it is easy to reach the aforementioned performance levels in the mild earthquakes in the moment frame structures with and without viscous dampers. However, in ED and CD performance levels, the changes are tangible and indicative of the proper performance of the tuned viscous damper for the reduction of the structure's destruction likelihood. The notable effect of the damper in the 9-storey frame is very much tangible in comparison to the other two frames for all the performance levels and this is suggestive of the damper's proper performance in reducing the destruction likelihood.

\subsection{Time History Analysis:}

In order to investigate the effect of damper on the structure's response subject to the last risk level as specified in Iran's earthquake guideline, the results of the time history analysis have been compared on certain models in two states of with and without viscous dampers. In order to perform time history analysis, the accelerogram introduced in table (3) is seminally scaled based on the instructions offered in Iran's earthquake guideline (standard 2800) to the region's demand spectrum for soil type 3 and return period of 475 years. After the exertion of each accelerogram, the maximum relative inter-storey displacement was extracted as the structure's response. 
As it is observed in figure (3), damper has a considerable effect on the controlling of the structures' response, especially the 9-storey structure (average height). Of course, the optimal effect of this energy depreciation system on the reduction of the structure's response cannot be explicitly expressed for the preliminary designing of the structure without damper, excitation type and other cases are amongst the important factors influencing the structure's response

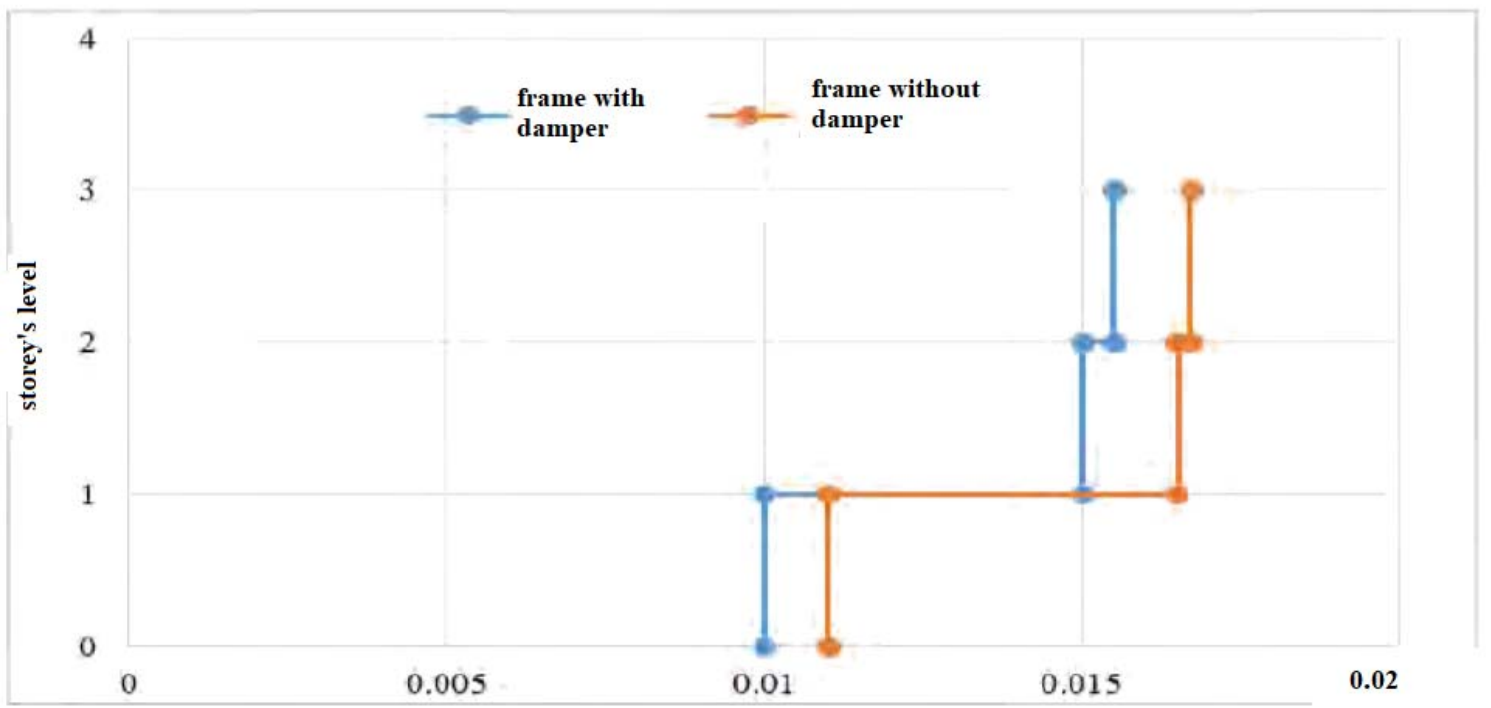

A) Three-storey frame

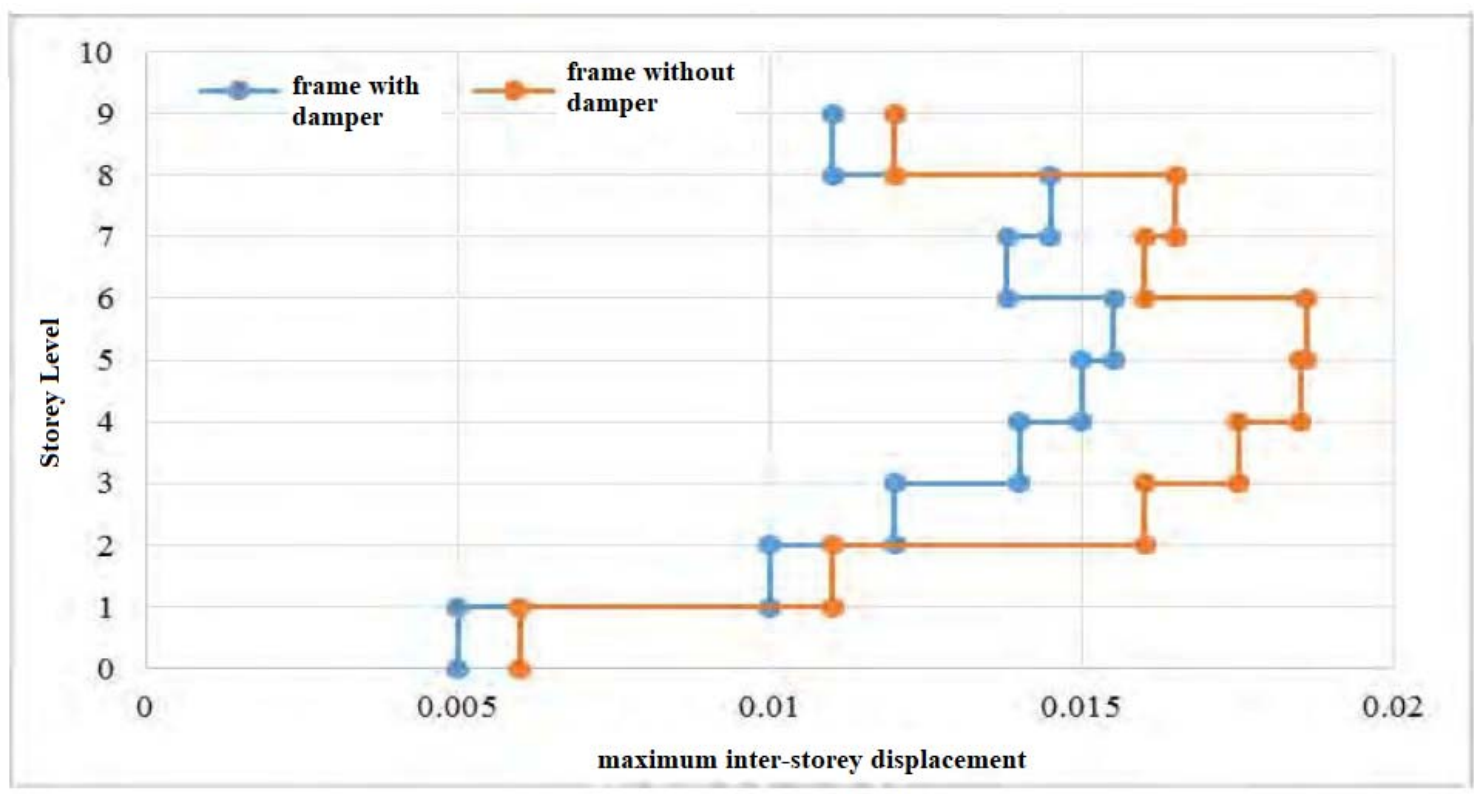

B) Nine-storey frame 


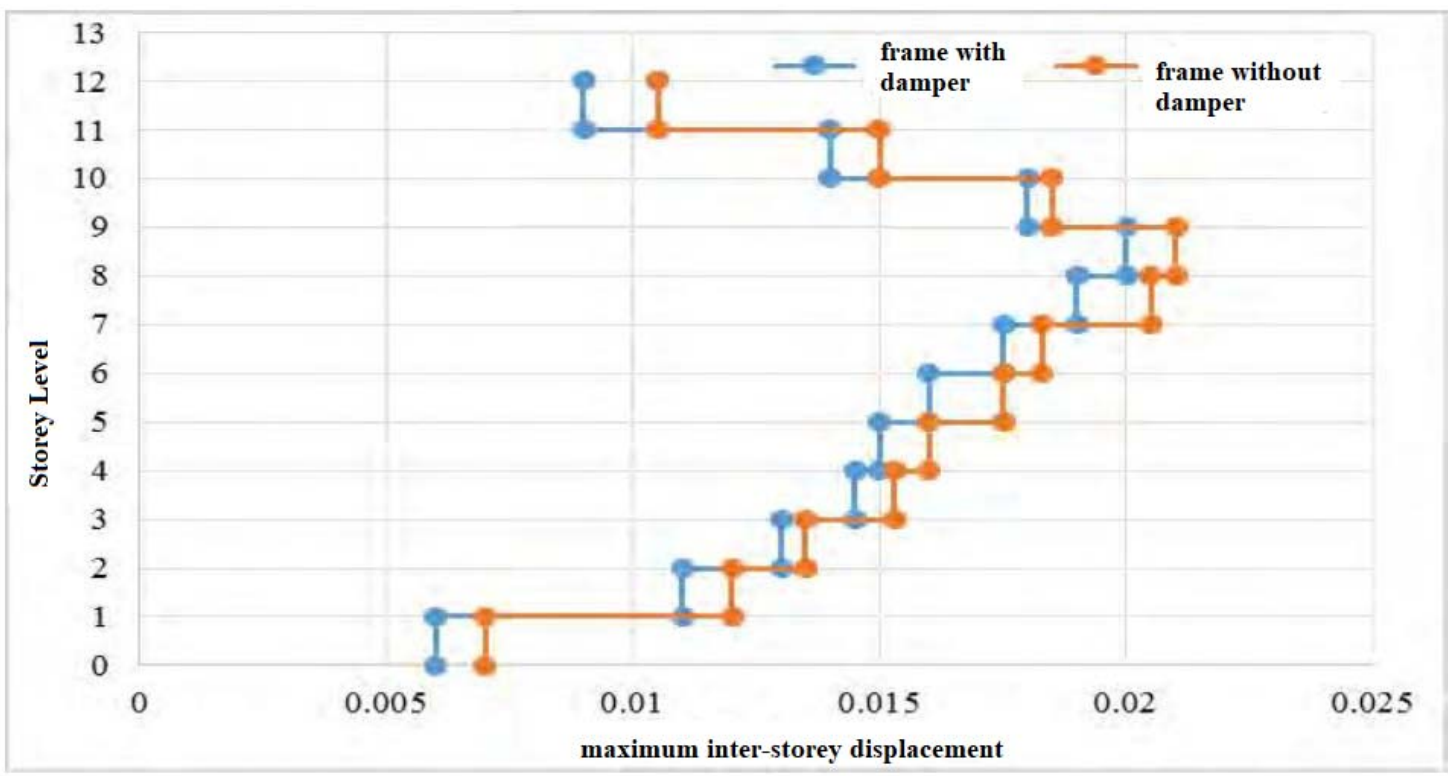

C) Twelve-storey frame

Image (3): the mean maximum relative inter-storey displacement as evidenced in the accelerograms scaled to Iran's earthquake designing spectrum guideline

Conclusion:

It is evident that the results obtained in this study are limited to the models and the hypotheses proposed herein and these results cannot be used for all of the future analytical models. The results obtained from this study are as summarized beneath:

- Disorder in viscous damper's setup can considerably increase or reduce the metal structures' destruction likelihood in the domain of nonlinear deformations. The amount of these effects are more prominent for mass and damping in contrast to the other items.

- Optimal simultaneous change in the mass and damping can bring about notable increase in the improvement of the structure's seismic performance in comparison to the certain states.

- Disorder in the structure's inherent damping in the form of increase therein for the two states of with and without damper would have a favorable effect on the reduction of the structure's response and the reverse also holds true.

- Disorder in the structure's mass exerts the highest effect on the structure's response for the two states of with and without viscous damper. The reduction in the mass of the structure equipped with damper in the studied 9-storey frame in complete destruction (CD) performance level causes an increase by $14.67 \%$ in the structure's seismic performance.

- The effect of the earthquake records' properties is well evident in the obtained behavior coefficient and this is due to the differences in intensity, duration and frequency content of the various earthquakes and it is confirmed according to the results obtained from five earthquake records that were utilized in the dynamic analysis.

- Considering the fact that an identical behavior coefficient has been recommended in the guidelines for all of the country's regions, it can be suggested that this coefficient is determined separately for the collection of the regions featuring identical ground quakes-motions' properties according to the effect of the ground quakes and motions on the structures' behavior coefficient.

\section{References:}

[1] Gholampour, S.; Taghipour, R. and Sanjarani, Sh., (2012), "studying the effect of using viscous dampers on the seismic response of the steel moment frames", 2nd national conference on structure, earthquake and geo-techniques, Babulsar, Pardisan Higher Education Institute

[2] "DEVICE FOR DAMPING VIBRATIONS OF BODIES." U.S. Patent .( $(9.9)$ HERMANN, F.. $90 \wedge, 9 \wedge 9$ Application. ${ }^{\Gamma}$

[3] "The theory of the dynamic vibration absorber." Trans., ASME, ( ( 9 $\uparrow$ ) Ormondroyd, J. . r Y_q,,$\circ$ Applied Mechanics,..

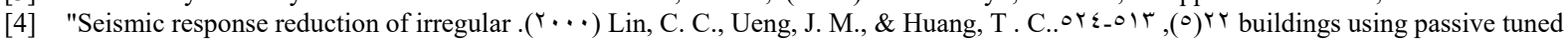
mass dampers." Engineering Structures,. ${ }^{\circ}$

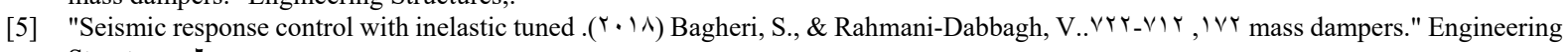
Structures, ${ }^{7}$

[6] "Nonlinear structural control .( ( • ।9) Karami, K., Manie, S., Ghafouri, K., \& Nagarajaiah, S., '^ । using integrated DDA/ISMP and semiactive tuned mass damper." Engineering Structures,. $\uparrow . \Sigma_{-} \diamond \wedge, . \vee$ 


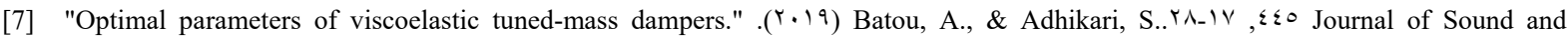
Vibration,.^

[8] "Frequency domain ( ( . १९) van Til, J., Alijani, F., Voormeeren, S. N., \& Lacarbonara, W.modeling of nonlinear end stop behavior in Tuned Mass Damper systems under single-and . 1 $r_{-} 1 \uparrow q, \leqslant \uparrow \wedge$ multi-harmonic excitations." Journal of Sound and Vibration,

[9] Kayhani, A.; Darbanian, R.; Mohsenian, V. and Naderi, R., (2015), "probabilistic evaluation of the effect of the inherent and cognitive uncertainties on the seismic performance of the steel structures equipped with tuned viscous dampers", MA dissertation, faculty of civil engineering, Shahrud University

[10] Ashrafi, P. and Alamatian, J., (2015), "designing viscous dampers for non-damped structures by combining stable and transient responses", journal of Ferdowsi Civil Engineering, 26(2)

[11] Sayyar, R. and Golnargesi, S., (2017), "investigating the effect of tuned viscous dampers on the behavior of the steel moment frame structures in various earthquakes", the 1st national conference on applied research in engineering sciences

[12] Farrokhi, F. and Rahimi, S., (2017), "probabilistic evaluation of the viscous dampers' performance in high steel structures", international conference on the novelties of the urban management, civil engineering and technology in modern architecture

[13] Rahmani Dabbagh, V., (2018), "tuned viscous damper for controlling the quakes of the nonlinear structures' system", the conference on the urban engineering of Islam world's countries, Tabriz, Tabriz University, Shahid Madani University, Azerbaijan, applied sciences and technology university of Tabriz's municipality

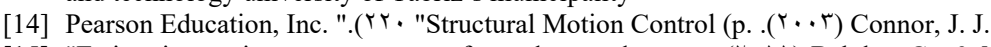

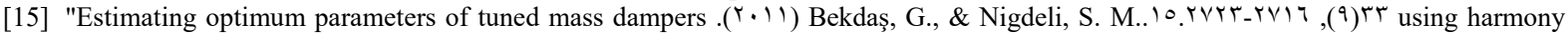
search." Engineering Structures,

[16] "Chapter six of national building regulations (loads imposed on the building)", 2013 edition, Tehran, the office for the building's national regulations affairs, Iran's development center press (center for the researches on road, housing and urban engineering)

[17] "Chapter ten of the national building regulations (designing and implementing steel buildings", 2013 edition, the office for the building's national regulations affairs, Iran's development center press (center for the researches on road, housing and urban engineering)

[18] "Guidelines for the seismic improvement of the existing buildings", (2013), 1st ed., journal 360, strategic monitoring affairs vice chancellorship, Tehran, technical system, Iran's development center press (center for the researches on road, housing and urban engineering)

[19] Guidelines of the buildings' design against earthquake (standard 2800: 4th ed.,)", (2013), the permanent committee of the designing procedures revision 